\title{
BILATERAL SYMMETRICAL CYSTIC DETACHMENT OF THE RETINA
}

\author{
BY \\ H. B. STALLARD \\ LONDON
}

Two cases of bilateral symmetrical cystic detachment of the retina pre-equatorial in the upper temporal quadrants of each eye are reported because such a condition is, I think, a rarity. In both cases the cysts were symmetrical in size, shape and position. In one case the cystic detachment in the right eye had spontaneously disappeared, the retina was replaced and there was no retinal hole. The periphery of the cyst in this case was marked posteriorly by a broad greyish-white crescent and the area of retina which had formed the thin stretched cystic wall and was now replaced showed a slightly deeper red fundus reflex than the remainder of the fundus. These fundus appearances were precisely those seen after successful reposition of the cystic detachment by surgical measures. In both cases there was no family history of cystic detachment nor any congenital ocular or other defect. The eyes of both patients were quite normal except for the cystic detachment. One had a low degree of myopia and the other was emmetropic. Neither was aware of the cystic detachments which were discovered in routine examinations. The vitreous appeared normal on ophthalmoscopic examination in each case, there were no congenital defects and no signs of any congenital anomaly elsewhere in their bodies. Operative treatment consisted of a single application of surface diathermy near the most dependent part of the cyst about half-way between the ora serrata and the equator. Through this site a single puncture was made with a fine penetrating diathermy needle $1.5 \mathrm{~mm}$. long. The cystic fluid was effectively evacuated and post-operative recovery was uneventful. The retina was replaced in the three eyes operated upon.

\section{Case notes}

(1) Spr. S. G. L., Royal Engineer, aged 22 years, came to 108 (Br) General Hospital on November 20, 1944 on account of conjunctivitis. Routine fundus examination showed cystic detachment of the retina in the upper temporal quadrant of each eye. This was between the ora serrata and the equator (see Fig. 1). R.V. 6/5. L.V. 6/9, both eyes emmetropic.

On December 1, 1944, the left eye was operated on and on December 29, 1944, the right eye was done. The retinae were replaced and remained so. On January 17, 1945, R.V. 6/5, L.V. $6 / 5$. Visual fields full. Schiötz tonometer readings R.E. $13 \mathrm{~mm}$. Hg. L.E. $12 \mathrm{~mm} . \mathrm{Hg}$. January 20, 1945, discharged to Convalescent Depot. Follow-up, retinae remained in place. 
(2) Pte. S. B., aged 34 years, was referred on January 26, 1945, to Major Hill, 23 (Scot) General Hospital, for routine examination and I am grateful to him for referring his case to me at $1.08(\mathrm{Br})$ General Hospital.

Fig. 2 shows the site of cystic retinal detachment in the right eye, which I believe at some time underwent spontaneous reposition of the retina. The greyish white crescentic band with its concavity anteriorly marks the posterior limit of the base of the cyst. In front of this is an area of thin retina, the subsided retinal cyst wall, through which the red fundus reflex shows more intensely than the rest of the fundus. There was no hole or split to be seen and the visual field was full. Schiötz tonometer reading was $12 \mathrm{~mm} . \mathrm{Hg}$.

As mentioned above the fundus appearances in the pre-equatorial region of the upper temporal quadrant of the right eye are similar to those after replacement of the retina by surgical diathermy and drainage of the cystic fluid, except of course there is here in addition the choroido-retinal scar made by the diathermy. R.V. 6/60 with - 4.0 sph. - 0.5 cyl. ax. 90. 6/6.

The left eye showed a cystic detachment of the retina in the upper temporal quadrant between the equator and ora serrata (see Fig. 2). L.V. 6/36 with $-2.0 \mathrm{sph} .6 / 6$. The Schiötz reading was $10.5 \mathrm{~mm} . \mathrm{Hg}$. On February 5, 1945, an operation was performed. The exposed sclera just above the upper margin of the external rectus muscle, half-way between the ora serrata and equator was touched with a single application of surface diathermy and this site was penetrated with a diathermy needle. Some syrupy cystic fluid came out.

The post-operative course was uneventful, the retina was replaced and on February 24, 1945, the visual field was full and the Schiötz reading $9 \mathrm{~mm} . \mathrm{Hg}$.

Why operate in such cases? My reason for so doing was based on the observation of 13 cases of cystic detachment of the retina seen in the M.E.F. 12 of these developed tears, 7 of these had multiple tears. In 2 cases there was a sudden spread of the detachment from beyond the limits of the cystic area which caused separation of the macula. One soldier in whom this occurred sought advice within a week of this catastrophe and the other four months later.

As it is impossible with troop movements in a field force to keep in touch with such cases and to have them up for periodic follow-up examinations I think it is safer to operate, for the results are and should be 100 per cent. successful.

Indeed this was so in the 13 cases operated on in the M.E.F. and 3 in the B.L.A. (one of these had both eyes operated onSpr. S. G. L., described in this paper). 


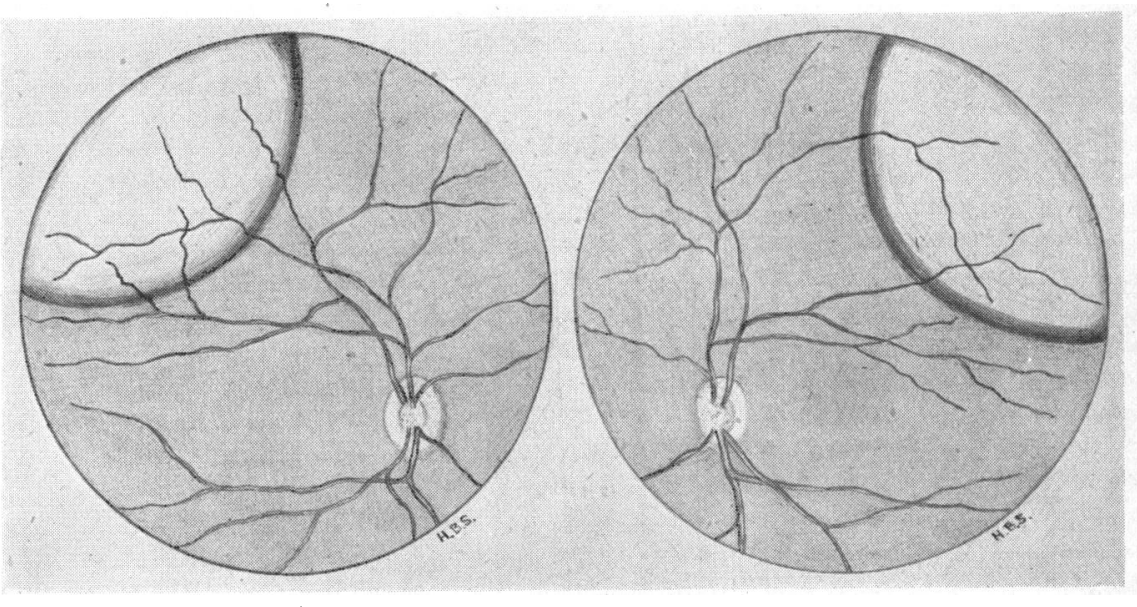

FIG. 1.

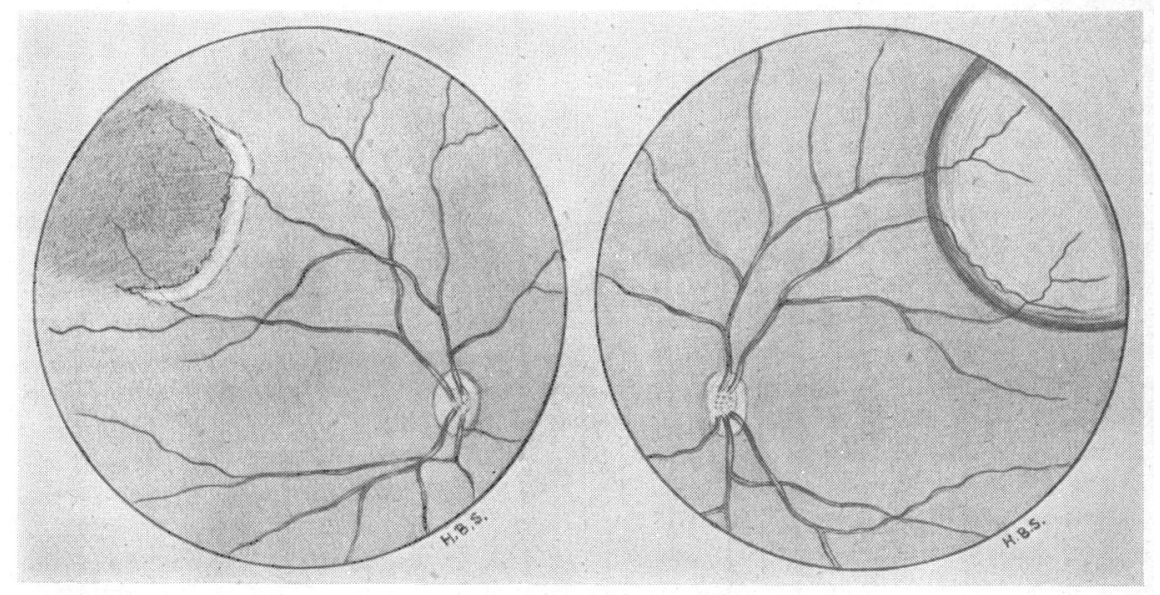

FIG. 2.

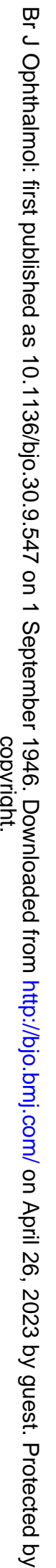

